\title{
THE INTRAVENOUS GLUCOSE TOLERANCE TEST IN PREGNANCY ${ }^{1}$
}

\author{
By DONALD G. JOHNSON AND ROY W. BONSNES \\ WITH THE TECHNICAL ASSISTANCE OF BEATRICE BARAD \\ (From the Department of Obstetrics and Gynecology, Cornell University Medical College, \\ and the New York Hospital, New York City)
}

(Received for publication June 28, 1948)

Since the introduction of the glucose tolerance test as a diagnostic aid the glucose has classically been administered by mouth. By this procedure the pregnant women may exhibit a normal tolerance to glucose or may in many instances exhibit a decreased tolerance to glucose (1-4). Selman (3), for instance, reports 22 out of 47 patients studied by him to show high, prolonged or high and prolonged blood glucose levels when judged by certain criteria. Hurwitz and Jensen (4) find normal fasting blood sugar levels and normal peaks, but 81 per cent of their pregnant series showed high blood sugar values at two hours. From these data these authors conclude that pregnancy exerts a deleterious effect on carbohydrate metabolism.

The disadvantages of the oral route of administration of the glucose are many and they have been pointed out by several authors (5-9). These disadvantages have led to the use of the intravenous route of administration $(8,9)$ as a better test of the ability of the subject to metabolize glucose. In pregnancy all the objections to the oral route of administration apply as they do in the nonpregnant individual. In addition, alterations in the gastrointestinal tract peculiar to pregnancy might complicate the picture further.

In view of these considerations we have determined the tolerance of pregnant women to intravenously administered glucose. The over-all procedure employed is essentially the same as the one described by Lozner, Winkler, Taylor and Peters (9) who have determined the tolerance of nonpregnant individuals to 25 grams of intravenously administered glucose.

\section{SUBJECTS AND METHODS}

Subjects were chosen from the obstetrical in-patient and out-patient services of the New York Hospital. Only

1 This study was aided by a grant from the John and Mary R. Markle Foundation, women whose course and past history were considered normal were chosen. Individuals with histories of previous glycosuria, or current diabetes, hypertension, kidney or liver disease were eliminated. The tests were performed on subjects at various stages of pregnancy. Subjects for control study were chosen from gynecological in-patients. They were all within the child-bearing age. Only those with benign conditions were selected.

There were 20 in the pregnant group. Their ages ranged from 17 to 43 years with an average age of 28.9 years. There were five in the fourth, three in the fifth, two in the sixth, three in the seventh, three in the eighth, one in the ninth, and three in the tenth lunar month of pregnancy. There were 11 in the non-pregnant group. Their ages ranged from 20 to 38 years with an average age of 28.9 years.

All subjects were in the post-absorptive state. Some were encouraged to drink 600 to $800 \mathrm{ml}$. of water before the test was started in order to promote urine flow. A No. 18 Foley indwelling catheter with a $5-\mathrm{ml}$. bag was placed in the bladder and the bladder emptied. A blood sample was withdrawn. Then $50 \mathrm{ml}$. of 50 per cent glucose were injected intravenously through a No. 18 needle in 45 to 60 seconds. Blood samples were then drawn at five, 15, 30, 60 and 120 minutes after the injection. Urine specimens were drawn at 15, 30, 60 and 120 minutes after the injection, the bladder being completely emptied but not washed out at the time of each collection.

Protein-free filtrates of the blood samples were made by the Folin-Wu method (10). Blood sugars were determined on these filtrates by the Benedict method (11). Quantitative urine sugars were determined on appropriately diluted urine specimens by the same method. The optical densities of the final colored solutions were determined in a Klett-Summerson photometer using filter 42 (12).

\section{RESULTS}

The blood sugar values for the pregnant and the control groups are presented in Table $I$ and are illustrated graphically in Figure 1 where the data of Lozner et al. are added for comparison. The values obtained by us for the control group parallel closely the values obtained by Lozner et al. The values obtained for the pregnant group, however, tend at all times to average slightly, though not significantly, lower than those of the control 
groups. At 60 minutes the average blood sugar value and the range of values observed in the pregnant group tend definitely to be lower than the average values observed in the control groups. The difference between the two means equals 3.09 standard errors of the difference between the two means when our data are used, and 2.72 when the data of Lozner et al. are used. These figures do not indicate a really significant difference.

The average values, the extreme observed values, and the standard deviation of the pregnant and the nonpregnant groups are summarized in Table II. The standard deviation was calculated in the usual way where the standard deviation

$$
\sigma=\sqrt{\frac{\Sigma d^{2}}{N-1}} .
$$

The amount of glucose excreted in the urine seems to be about the same in both the pregnant and the nonpregnant groups. These values are, however, nearly twice that reported by Lozner et al.

\section{DISCUSSION}

From these results it would appear that the pregnant women can tolerate intravenously injected glucose as well as, if not better than, the nonpregnant women. The tendency for the blood sugar levels of the pregnant women to fall toward fasting levels more rapidly, i.e., to have slightly lower blood sugar values at 60 minutes after the injection of the glucose, might indicate a slight increase in the rate of utilization of the glucose, or a greater total volume in which to dilute the glucose or a decreased kidney tubular reabsorptive capacity for glucose (kidney threshold). Or all three of these factors might be operating simultaneously to some extent.

Our present data (the average amount of glucose found in the urine of the pregnant and the

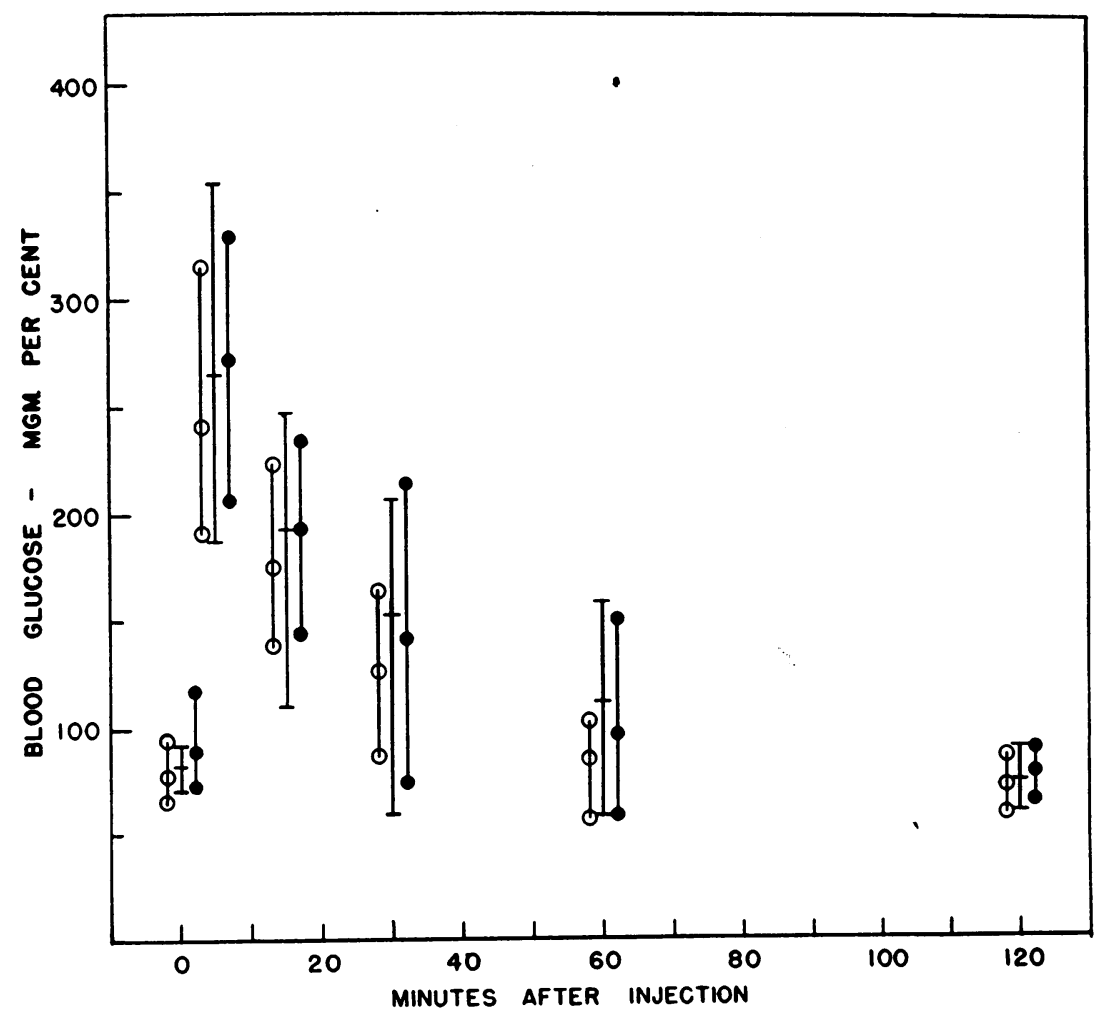

Fig. 1. Graph of Results of Intravenous Glucose Tolerance Tests

Open circles indicate data from pregnant women, horizontal lines from normal women and dots from Lozner et al. (9). The upper and lower circles (lines or dots) indicate the extremes observed; the central circle the average value. The vertical lines are visual guides. The data from pregnant women are plotted two minutes early and the data from Lozner et al. two minutes late. 
TABLE I

Distribution of values

\begin{tabular}{|c|c|c|c|c|c|c|c|c|c|}
\hline & $\underset{\text { ber }}{\text { Num- }}$ & Age & $\begin{array}{c}\text { Dura- } \\
\text { tion } \\
\text { preg. } \\
\text { (wks.) }\end{array}$ & $\begin{array}{c}\text { Fast- } \\
\text { ing }\end{array}$ & $5 \mathrm{~min}$. & $15 \mathrm{~min}$ & $30 \mathrm{~min}$. & $60 \mathrm{~min}$. & $120 \mathrm{~min}$. \\
\hline 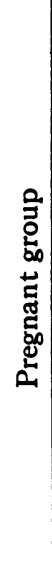 & $\begin{array}{r}1 \\
2 \\
3 \\
4 \\
5 \\
6 \\
7 \\
8 \\
9 \\
10 \\
11 \\
12 \\
13 \\
14 \\
15 \\
16 \\
17 \\
18 \\
19 \\
20\end{array}$ & $\begin{array}{l}29 \\
39 \\
23 \\
43 \\
23 \\
21 \\
23 \\
33 \\
37 \\
30 \\
34 \\
17 \\
25 \\
36 \\
21 \\
35 \\
32 \\
24 \\
31 \\
22\end{array}$ & $\begin{array}{l}29 \\
40 \\
15 \\
22 \\
18 \\
15 \\
39 \\
30 \\
22 \\
32 \\
20 \\
26 \\
34 \\
15 \\
26 \\
37 \\
20 \\
27 \\
13 \\
15\end{array}$ & $\begin{array}{l}69 \\
65 \\
82 \\
83 \\
90 \\
68 \\
69 \\
79 \\
84 \\
78 \\
94 \\
75 \\
70 \\
79 \\
69 \\
79 \\
79 \\
74 \\
77 \\
81\end{array}$ & $\begin{array}{l}-\overline{198} \\
202 \\
245 \\
206 \\
231 \\
222 \\
224 \\
257 \\
250 \\
243 \\
286 \\
220 \\
315 \\
230 \\
191 \\
258 \\
315 \\
237 \\
245\end{array}$ & $\begin{array}{l}152 \\
170 \\
170 \\
171 \\
154 \\
143 \\
149 \\
181 \\
161 \\
213 \\
179 \\
210 \\
163 \\
138 \\
160 \\
167 \\
218 \\
191 \\
179 \\
223\end{array}$ & $\begin{array}{r}126 \\
130 \\
147 \\
127 \\
93 \\
96 \\
109 \\
137 \\
131 \\
139 \\
137 \\
156 \\
133 \\
99 \\
106 \\
86 \\
165 \\
118 \\
118 \\
164\end{array}$ & $\begin{array}{r}79 \\
99 \\
92 \\
92 \\
81 \\
56 \\
74 \\
108 \\
97 \\
78 \\
96 \\
103 \\
96 \\
75 \\
83 \\
69 \\
91 \\
62 \\
72 \\
97\end{array}$ & $\begin{array}{l}59 \\
63 \\
66 \\
73 \\
86 \\
84 \\
63 \\
71 \\
63 \\
75 \\
73 \\
78 \\
70 \\
74 \\
74 \\
70 \\
75 \\
76 \\
68 \\
78\end{array}$ \\
\hline 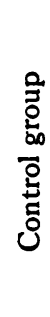 & $\begin{array}{r}1 \\
2 \\
3 \\
4 \\
5 \\
6 \\
7 \\
8 \\
9 \\
10 \\
11\end{array}$ & $\begin{array}{l}30 \\
24 \\
30 \\
22 \\
25 \\
27 \\
20 \\
26 \\
38 \\
29 \\
25\end{array}$ & & $\begin{array}{l}79 \\
92 \\
83 \\
79 \\
80 \\
84 \\
86 \\
91 \\
70 \\
70 \\
85\end{array}$ & $\begin{array}{l}229 \\
230 \\
300 \\
187 \\
273 \\
245 \\
301 \\
354 \\
271 \\
244 \\
282\end{array}$ & $\begin{array}{l}174 \\
195 \\
200 \\
138 \\
217 \\
192 \\
195 \\
247 \\
111 \\
211 \\
240\end{array}$ & $\begin{array}{r}117 \\
162 \\
130 \\
123 \\
189 \\
159 \\
174 \\
183 \\
58 \\
178 \\
207\end{array}$ & $\begin{array}{r}66 \\
147 \\
82 \\
84 \\
134 \\
103 \\
136 \\
107 \\
58 \\
152 \\
160\end{array}$ & $\begin{array}{l}73 \\
72 \\
66 \\
69 \\
79 \\
60 \\
78 \\
77 \\
73 \\
90 \\
91\end{array}$ \\
\hline
\end{tabular}

nonpregnant groups) do not indicate a marked decrease in the kidney tubular reabsorptive capacity for glucose in the pregnant women. It must be admitted, however, that the average value for the amount of glucose found in the urine in the pregnant group is about twice the amount observed by
Lozner et al. Since, however, we obtained a value of the same order of magnitude in our pregnant and nonpregnant groups, the discrepancy may be due to the use of different methods for the determination of the urine sugar. The actual determination of the maximal kidney tubular reabsorptive capacity for glucose in the pregnant women will answer this question.

Since the glucose tolerance test becomes more like that observed in the nonpregnant women in the early puerperium, one factor operating toward this tendency toward lower values at 60 minutes following the administration of the glucose may be the increased total volume in which the glucose may be distributed. When equilibrium is reestablished essentially normal values obtain. On the other hand, no correlation with the time of pregnancy can be seen if the data are arranged in order of the weeks pregnant. Several different mechanisms may, therefore, operate to produce this tendency.

Intravenously injected glucose seems, then, to be removed from the blood of pregnant women at essentially the same rate as from the blood of nonpregnant women. It becomes difficult now to explain the previously reported tendency toward a decreased tolerance of pregnant women to glucose administered by mouth. This apparent paradox needs further elucidation.

This contradiction in results obtained by the intravenous and the oral glucose tolerance test in pregnancy shows the oral route of administration,

TABLE II

Analysis of data of pregnant and control groups

\begin{tabular}{|c|c|c|c|c|c|c|c|c|c|c|c|}
\hline \multicolumn{6}{|c|}{ Pregnant group } & \multicolumn{6}{|c|}{ Control group } \\
\hline \multirow{2}{*}{$\begin{array}{l}\text { Minutes } \\
\text { after } \\
\text { injection }\end{array}$} & \multirow{2}{*}{$\begin{array}{l}\text { Number } \\
\text { of } \\
\text { subjects }\end{array}$} & \multicolumn{4}{|c|}{ Glucose in mgm. per $100 \mathrm{cc}$. blood } & \multirow{2}{*}{$\begin{array}{l}\text { Minutes } \\
\text { after } \\
\text { injection }\end{array}$} & \multirow{2}{*}{$\begin{array}{c}\text { Number } \\
\text { of } \\
\text { subjects }\end{array}$} & \multicolumn{4}{|c|}{ Glucose in mgm. per $100 \mathrm{cc}$. blood } \\
\hline & & Max. & Min. & Aver. & $\begin{array}{l}\text { Stand. } \\
\text { devia. }\end{array}$ & & & Max. & Min. & Aver. & $\begin{array}{l}\text { Stand. } \\
\text { devia. }\end{array}$ \\
\hline $\begin{array}{r}0 \\
5 \\
15 \\
30 \\
60 \\
120\end{array}$ & $\begin{array}{l}20 \\
19 \\
20 \\
20 \\
20 \\
20\end{array}$ & $\begin{array}{r}94 \\
315 \\
223 \\
164 \\
103 \\
86\end{array}$ & $\begin{array}{r}65 \\
191 \\
138 \\
86 \\
56 \\
59\end{array}$ & $\begin{array}{r}77 \\
241 \\
175 \\
126 \\
85 \\
72\end{array}$ & $\begin{array}{r}7 \\
35 \\
25 \\
23 \\
14 \\
7\end{array}$ & $\begin{array}{r}0 \\
5 \\
15 \\
30 \\
60 \\
120\end{array}$ & $\begin{array}{l}11 \\
11 \\
11 \\
11 \\
11 \\
11\end{array}$ & $\begin{array}{r}92 \\
354 \\
247 \\
207 \\
160 \\
91\end{array}$ & $\begin{array}{r}70 \\
187 \\
111 \\
58 \\
58 \\
60\end{array}$ & $\begin{array}{r}82 \\
265 \\
193 \\
153 \\
112 \\
75\end{array}$ & $\begin{array}{r}7 \\
45 \\
40 \\
42 \\
36 \\
9\end{array}$ \\
\hline \multicolumn{6}{|c|}{ Average urine excretion $7.2 \%$} & \multicolumn{6}{|c|}{ Average urine excretion $6.8 \%$} \\
\hline
\end{tabular}


with its undesirable and uncontrollable factors in the nonpregnant state, to be less desirable in the pregnant state. Further, there is less objection on the part of the patient to the intravenous administration of 50 per cent glucose than to the ingestion of large quantities of glucose by mouth. In this series the rate of administration of the glucose was as rapid as possible using a No. 18 gauge needle. The only complaint registered by the patients in all instances was a sensation of "warmth" first appearing at the site of the injection and later in the neck. The sensation appeared within 30 seconds of the start of the injection and had completely vanished within 30 seconds of the completion of the injection.

\section{SUM MARY}

Intravenous glucose tolerance tests have been performed on 20 pregnant women and on 11 nonpregnant women within the childbearing age. The intravenously injected glucose disappears from the blood of the pregnant women at essentially the same rate as from the blood of nonpregnant women. There is a tendency for the blood sugar of the pregnant women to return to fasting levels more rapidly than of the nonpregnant individuals. These results are discussed. It is concluded that the tolerance for intravenously injected glucose is essentially the same in the pregnant women as in the nonpregnant women of childbearing age.

\section{BIBLIOGRAPHY}

1. Labbé, M., and Chevki, M., Le trouble de la glycorégulation chez femmes encientes. Compt. rend. Soc. biol., 1926, 94, 302.

2. Williams, E. C. P., and Willis, L., Studies in blood and urinary chemistry during pregnancy; blood sugar curves. Quart. J. Med., 1929, 22, 493.

3. Selman, J. J., The results of glucose tolerance tests in pregnant women. Ohio State M. J., 1932, 28, 184.

4. Hurwitz, D., and Jensen, D., Carbohydrate metabolism in normal pregnancy. New England J. Med., 1946, 234, 327.

5. Hale-White, R., and Payne, W. W., The dextrose tolerance curve in health. Quart. J. Med., 1926, 19, 393.

6. Thaysen, T. E. H., Blood sugar regulation in idiopathic steatorrhea. Arch. Int. Med., 1929, 44, 477.

7. Myers, G. B., and McKean, R. M., The oral glucose tolerance tests: a review of the literature. Am. J. Clin. Path., 1935, 5, 299.

8. Tunbridge, R. E., and Allibone, E. C., The intravenous dextrose tolerance test. Quart. J. Med., 1940, 9, 11.

9. Lozner, E. L., Winkler, A. W., Taylor, F. H. L., and Peters, J. P., The intravenous glucose tolerance test. J. Clin. Invest., 1941, 20, 507.

10. Folin, O., and Wu, H., A system of blood analysis. J. Biol. Chem., 1919, 38, 81.

11. Benedict, S. R., The analysis of whole blood. II. The determination of sugar and of saccharoids (nonfermentable copper-reducing substances). J. Biol. Chem., 1931, 92, 141.

12. Summerson, W. H., A simplified test-tube photoelectric colorimeter, and the use of the photoelectric colorimeter in colorimetric analysis. J. Biol. Chem., 1939, 130, 149. 